\title{
PENERAPAN HYGIENE DAN SANITASI DALAM PENYIMPANAN BAHAN BAKU MAKANAN DI HOTEL X JAKARTA
}

\author{
Trias Septyoari Putranto ${ }^{1)}$ \\ 1) Hotel Management, Universitas Bina Nusantara \\ 5 November 2018
}

\begin{abstract}
This research aims to explain the application of hygiene and sanitation in the storage of food raw ingredients at Hotel X Jakarta. The research method used is qualitative through observation, interview and documentation at Hotel X Jakarta. The results of the application of the method of storing raw ingredients in dry store and in chiller at Buzz. Kitchen have implemented cleanliness by conducting FIFO for each storage of food ingredients. The use of cleanliness of storage of raw ingredients in dry store and in chillers in Buzz kitchen has implemented cleanliness by cleaning storage space. Changed plastic wrap for foodstuffs stored in containers and covered with the new plastic wrap. The application of kitchen area cleanliness to western section, Asian section and cold section has applied the cleanliness of the kitchen area by cleaning stains on the floor, stains on the table, and not letting the garbage accumulate to much
\end{abstract}

Keyword: Hotel X Jakarta, Hygiene, Sanitation, Dry Storage, Chiller Storage, Kitchen Area

\begin{abstract}
ABSTRAK
Penelitian ini bertujuan untuk mempelajari penerapan hygiene dan sanitasi dalam penyimpanan bahan baku makanan di Hotel X Jakarta. Metode penelitian yang digunakan adalah kualitatif dengan melakukan observasi, wawancara dan dokumentasi di Hotel X Jakarta. Hasil penelitian penerapan cara penyimpanan bahan baku pada dry store dan chiller di Buzz kitchen sudah menerapkan hygiene dengan melakukan FIFO untuk setiap penyimpanan bahan makanan. Penerapan kebersihan tempat penyimpanan bahan baku pada dry store dan chiller di Buzz kitchen sudah menerapkan kebersihan dengan membersihkan tempat penyimpanan. Mengganti plastik wrap kepada bahan makanan yang disimpan didalam container dan ditutup dengan plastik wrap. Penerapan kebersihan area dapur pada western section, Asian section dan cold section sudah menerapkan kebersihan area dapurnya dengan membersihkan noda pada lantai, noda di atas meja, dan tidak membiarkan sampah menumpuk begitu banyak..
\end{abstract}

Kata Kunci: Hotel X Jakarta, Hygiene, Sanitasi, Penyimpanan Bahan Baku, Tempat Penyimpanan Kering, Tempat Penyimpanan Dingin, Dapur.

\section{PENDAHULUAN}

Bisnis Hotel berbeda dengan bisnis yang lainnya, kesuksesan dari bisnis hotel dikarenakan para pemilik ataupun pengelola hotel lebih banyak menitik beratkan kepada faktor Sumber Daya Manusia sebagai pelaksana (Asta Media, 2018)

Letak lokasi yang strategis, harga, fasilitas, promosi, karyawan yang berdedikasi, kebersihan yang dijaga menjadi salah satu kunci menjalankan usaha hotel (Oktavianus, 2017). Dekat dengan area perkantoran dan stasiun kereta api, tidak heran Hotel X Jakarta dijadikan tujuan utama pebisnis dari dalam dan luar negeri untuk mengadakan rapat (meeting) atau sekedar menjadi tempat istirahat.

Hotel X Jakarta memiliki restoran bernama restoran Buzz, restoran Buzz merupakan restoran utama untuk mengolah dan menyediakan berbagai hidangan makanan Asia dan Western. Agar menghasilkan produk yang baik, bersih, sehat dan aman untuk dikonsumsi diperlukan penerapan hygiene dan sanitasi yang baik dan benar agar setiap produk yang disajikan kepada tamu selalu dalam kualitas baik (Legesse, 2017). Oleh karena itu, restoran 
Buzz menjalankan kebersihan setiap harinya dengan memeriksa setiap bahan makananannya setiap hari menggantikan makanan yang sudah kurang baik dengan baru, lantai yang selalu dibersihkan, sampah yang buang sebelum penuh, dan lain sebagainya.

Selain itu restoran Buzz juga melaksanakan kebersihan ditempat - tempat penyimpanannya. Ada beberapa syarat yang harus di perhatikan yaitu tempat penyimpanan yang baik. Menurut Milan ASL Preventive Medicine Department (2013:10), tempat penyimpanan yang baik adalah (1) Memiliki tempat/ rak penyimpanan yang memisahkan antara bahan mentah dan juga bahan yang siap dimakan, (2) Tinggi tempat penyimpanan tidak lebih dari 2 meter, (3) Bagian luar tempat penyimpanan dilindung agar tidak ada mikroorganisme yang mengkontaminasi, (4) Lantai yang aman atau tidak licin, dinding yang mudah dibersihkan, dan penerangan yang cukup./

Hygiene dan sanitasi di Hotel X Jakarta juga merupakan hal yang penting diterapkan untuk mencegah terjadinya keluhan tamu. Penerapan hygiene dan sanitasi mencakup banyak hal seperti kebersihan dan kesehatan penjamah makanan (personal hygiene). Setiap orang yang bekerja di area penanganan makanan harus menjaga tingkat kebersihan pribadi yang tinggi. Laki-laki atau perempuan harus memakai pakaian yang sesuai dan bersih dan, jika perlu, pakaian pelindung (Bennet, 2013). Hal ini perlu diperhatikan karena para penjamah makanan terlibat langsung dalam proses pembuatan produk makanan untuk tamu, bila penjamah makanan tidak memenuhi standar kesehatan yang ada maka tidak menutup kemungkinan makanan akan terkontaminasi oleh penjamah makanan itu sendiri.

Selain personal hygiene, kebersihan area kerja dan peralatan kerja di kitchen Hotel X Jakarta juga merupakan hal penting yang perlu diperhatikan. Semua barang, peralatan dan perlengkapan yang disentuh makanan, harus dibersihkan secara efektif. Untuk menghindari risiko kontaminasi peralatan terbuat dari bahan yang sesuai dan disimpan dengan baik, diperbaiki dan kondisi, dengan cara yang meminimalkan risiko apapun dari kontaminasi (Bennet, 2013).

Selain itu proses penyimpanan bahan makanan mentah dan produk jadi pun perlu di perhatikan, karena bila salah dalam proses penyimpananya, bahan dan produk makanan akan rusak dan bila terus dipakai bahan makanan, produk akan terkontaminasi oleh bakteri yang tumbuh dalam bahan makanan dan produk tersebut (Milan ASL Preventive Medicine Department, 2013).

Berdasarkan latar belakang, permasalahan yang dibahas pada penelitian ini adalah:

1. Bagaimana penerapan cara penyimpanan bahan baku di Buzz Kitchen?

2. Bagaimana penerapan kebersihan tempat penyimpanan di Buzz Kitchen?

3. Bagaimana penerapan kebersihan area dapur di Buzz Kitchen?

Tujuan penelitian ini adalah:

1. Untuk membahas tentang penerapan cara penyimpanan bahan baku di Buzz Kitchen

2. Untuk membahas tentang penerapan kebersihan tempat penyimpanan di Buzz Kitchen,

3. Untuk membahas tentang penerapan kebersihan area dapur di Buzz Kitchen

\section{METODE PENELITIAN}

Pada penelitian ini penulis menggunakan desain penelitian kualitatif. Menurut Sarwono (2013), desain penelitian kualitatif bersifat fleksibel dan berubah-ubah sesuai dengan kondisi lapangan. Data primer penulis ambil berdasarkan hasil wawancara bersama beberapa responden di Hotel X Jakarta dan beberapa hasil dokumentasi yang penulis dapatkan didalam hasil observasi penulis. Penulis ambil teori yang berhubungan dengan tempat penyimpanan yaitu dari buku BC Cook Articulation, Junal Milan ASL Preventive Medicine Departement. Metode pengumpulan data yang dilakukan adalah dengan meninjau lebih langsung ke dalam tempat penelitian 
dengan cara melakukan observasi selama 6 bulan di Hotel X, mewawancarai 5 orang responden yaitu 1 orang Jr. Sous Chef, adalah orang yang bertanggung jawab dalam kebersihan tempat penyimpanan bahan baku, 2 orang Chef de Partie, adalah orang yang melakukan kebersihan tempat penyimpanan, dan 2 orang Cook, adalah orang yang melaksanakan bersih-bersih disetiap penyimpanan, mencantumkan foto mengenai dapur dan tempat penyimpanan seperti chiller dan dry store dibagian Buzz kitchen, Buku panduan penulis dari buku BC Cook Articulation, jurnal Milan ASL Preventive Medicine Departement.

\section{HASIL DAN PEMBAHASAN Penerapan Proses Penyimpanan Bahan Baku di Buzz Kitchen}

Melakukan FIFO (first in first out). Dimana makanan yang disimpan pertama kali harus dipakai terlebih dahulu. Sistem FIFO dilakukan untuk menjaga makanan agar tidak terjadinya pembusukan makanan dan penumpukan makanan.

Memberikan label makanan berupa sticker yang tercantum dalam label yaitu nama produk (Kerupuk Udang), tanggal membuka kemasan (30/7/18), tanggal kadaluarsa yang tertera pada kemasan makanan tersebut di tulis kembali untuk mengingatkan (28/02/19) kepada makanan, dan nama orang penyimpanan makanan tersebut (Andy) seperti contoh makanan yang diberikan label makanan setelah dibuka: Plastik kemasan kerupuk mentah, plastik bumbu kering, kemasan chicken powder. Label makanan disimpan didalam kotak transparan dan ditaruh berdekatan dengan plastik wrap untuk memudahkan untuk dilihat dan diletakkan dibawah meja kerja.

Mengelompokan makanan kemasan bahan baku berupa kaleng (red bean, corn, tomato paste), botol kaca (sesame oil, mushroom paste, fish oil), plastik (kerupuk mentah, bumbu kering) dan kemasan kardus cerial sesuai dengan kelompoknya.

Pemasukan makanan yang diambil dari main store lalu ditata dengan rapih sesuai dengan kategorinya, apabila rak tidak ada ruang untuk menyimpan karena masih adanya bahan tersebut, maka makanan tersebut tidak dikeluarkan dari dalam kardus. Namun apabila makanan menumpuk tidak memakai kardus, maka bahan di simpan didalam container plastik dan disimpan dipaling atas khusus untuk makan kering saja tidak untuk bahan baku dari botol kaca. Apabila bahan yang menumpuk adalah yang berbotol kaca, maka bahan tersebut disimpan di area dapur. Tentunya dengan melakukan FIFO.

Selain menutup bahan baku makanan (mushroom sauce, blackpepper sauce, tomato paste yang sudah di pindahkan ke dalam container dari kemasan kaleng, barbeque sauce, sayuran, buah) dengan plastik wrap, atau dengan penutup container, atau dengan cara memvakum bahan baku (daging sapi, ikan, dan poultry/ unggas) tersebut dengan keadaan kondisi plastik vakum yang baik dan tidak memiliki lubang udara

Dengan cara memvakumnya dengan jarak yang dekat dengan bahan baku tersebut untuk mengurangi adanya udara yang tersimpan didalam plastik vakum. Dengan mengeluarkan bahan makanan dari frozen ke chiller dengan sangat minimal, per harinya bahan baku makanan dikeluar 3(tiga) sampai 4 (empat) buah saja.

\section{Penerapan Kebersihan Tempat Penyimpanan di Buzz Kitchen}

Membersihkan dry store 1(satu) minggu sekali. Pembersihan biasanya dilakukan pada hari sabtu atau minggu, pembersihan bergantung kepada kondisi restoran Buzz dalam keadaan tidak cukup ramai atau tidak ada buffet. Karyawan dan anak training bekerja sama dalam waktu pembersihan tersebut. Pembersihan dilakukan dengan menata bahan baku menjadi rapih sesuai dengan kelompoknya seperti makanan kaleng dengan makanan kaleng contohnya red bean, corn, tomato paste, botol kaca dengan botol kaca contohnya sesame oil, fish oil, makanan plastik dengan makanan plastik contohnya kerupuk, mie telor, bihun. Menghilangkan debu yang terdapat pada rak penyimpanannya, sisa-sisa bahan yang terjatuh di atas rak. Hal tersebut 
dapat menumbuhkan bakteri pada tempat penyimpanan tersebut dan dapat mengkontaminasi bahan makanan lain.

Membersihkan lantai dry store yang dilakukan oleh steward dengan menyapu, dan mengepel. Steward melakukan pembersihan setelah karyawan dan anak training selesai merapihkan area dry store tersebut. Pembersihan bertujuan untuk menjaga dry store tetap bersih dan terhindar dari kuman.

Menutup makanan dengan plastik wrap yang di terdapat disetiap sectionnya, dan diberi label berupa sticker yang tercantum nama produk (tomato paste), tanggal pembukaan produk atau tanggal makanan tersebut akan disimpan, dan tanggal expired, label makanan disimpan didalam kotak transparan dan ditaruh berdekatan dengan plastik wrap untuk memudahkan untuk dilihat dan diletakkan dibawah meja kerja, selain dengan plastik wrap makanan ditutup dengan penutup containernya langsung.

\section{Penerapan Kebersihan Area Dapur Di Buzz Kitchen}

Steward akan membersihkan secara rutin apabila lantai sudah terlihat kotor atau ada saluran air yang tidak lancar. Setiap 1 jam sekali steward akan memeriksa ke area dapur untuk melihat kondisi kebersihan lantainya. Apabila sudah mulai kotor steward akan segera membersihkannya.

Tidak membiarkan sampah menumpuk banyak, sampah yang terdapat di Buzz kitchen tidak dipisahkan sesuai dengan kategorinya, sampah dijadikan 1(satu) tempat sampah, maka apabila sampah sudah mulai menumpuk, steward akan mengganti plastik sampah dengan yang baru.

Membersihkan setiap kompor setelah dipakai proses masak agar terlihat rapih dan bersih, dan meja yang dibersihkan setiap kali selesai pakai untuk memotong. Area kompor dan meja harus terlihat bersih dan rapih. Membersihkannya dengan cara cuci meja dengan sabun, lap dengan kain bersih, lalu semprotkan bahan sanitasi keatas meja.

Steward akan mencuci peralatan yang kotor seperti stainless bowl sesudah dipakai, spatula setelah pakai. Steward akan mengambil peralatan apabila sudah digunakan lagi untuk segera dicuci, namun terkadang penjamah makanlah yang menaruh sendiri kedalam sink steward untuk dicuci.

Meja yang dibersihkan setiap kali selesai pakai untuk memotong. Area meja harus terlihat bersih dan rapih karena didalam cold kitchen terdapat makanan yang bersifat ready to eat dimana tidak ada proses masak kembali seperti buah, yoghurt, condiment salad (carrot, paprika, bawang bombay, zucchini, red bean, kacang polong), apabila makanan terkena meja yang tidak bersih, maka makanan tersebut akan terkena kontaminasi makanan. Membersihkannya dengan cara cuci meja dengan sabun, lap dengan kain bersih, lalu semprotkan bahan sanitasi keatas meja.

\section{SIMPULAN}

Penerapan cara penyimpanan bahan baku pada dry store dan chiller di Buzz kitchen sudah menerapkan hygiene dengan melakukan FIFO untuk setiap penyimpanan bahan makanan, menutup setiap bahan makanan yang disimpan didalam container dan memberikan label makanan disetiap bahan baku yang akan disimpan kedalam tempat penyimpanan. Namun terdapat 6 kajian yang belun diterapkan yaitu menerima kemasan kaleng yang rusak, tidak mengukur suhu bahan makanan hanya bergantung kepada suhu thermometer chiller, tidak menservis chiller secara rutin, terdapat plastik vakum yang kurang erat masih memiliki oksigen didalamnya, adanya plastik wrap yang tidak rapat di chiller dapat menimbulkan kontaminasi.

Penerapan kebersihan tempat penyimpanan bahan baku pada dry store dan chiller di Buzz kitchen sudah menerapkan kebersihan dengan membersihkan tempat penyimpanan, mengganti plastik wrap kepada bahan makanan yang disimpan didalam container dan ditutup dengan plastik wrap, mengganti mengganti container dan mencuci container setiap harinya untuk menjaga kebersihan bahan baku tersebut. Namun terdapat 2 kajian yang belum diterapkan yaitu suhu ruang tempat penyimpanan di dry store kurang sejuk atau masih lembab, dan masih adanya makanan matang disimpan berdekatan dengan makanan matang dikarenakan ruang yang kurang luas. 
Penerapan kebersihan area dapur pada western section, Asian section dan cold section sudah menerapkan kebersihan area dapurnya dengan membersihkan noda pada lantai, noda di atas meja, dan tidak membiarkan sampah menumpuk begitu banyak. Melakukan deep cleaning yaitu dengan menyikat lantai dapur, membersihkan dan mengganti plastik wrap, membersihkan rak penyimpanan dan memeriksa baku baku makanan yang mulai membusuk untuk segera dibuang agar tidak tercampur dengan bahan baku lainnya. Namun terdapat 2 kajian yang belum diterapkan yaitu tidak mengelompokan alat pengolahan makanan dan lantai dapur yang licin.

\section{Saran Praktisi}

Penulis memberikan beberapa saran kepada perusahaan yaitu

1. Meningkatkan penerapan hygiene terutama di daerah tempat penyimpanan kering, untuk menghindari makanan terkontaminasi terhadap bakteri. Suhu didalam ruangan harus terjaga agar mengurangi pertumbuhan bakteri.

2. Perhatikan setiap kemasan makanan yang akan disimpan atau yang telah disimpan, apabila plastik kemasan atau plastik wrap makanan terbuka akan menimbulkan kontaminasi terhadap makanan tersebut. Apabila kemasan plastik vakum terbuka di dalam freezer akan menimbulkan freezer burn.

3. Memeriksa bahan baku agar tidak tercampur dengan bahan baku yang sudah busuk.

4. Mempertahankan kebersihan pada setiap sectionnya, hal ini untuk mendukung kesehatan diarea dapur dan bahan bakunya agar tidak tercemar kontaminasi.

5. Meningkatkan penerapan hygiene untuk tempat penyimpanan chiller dengan pastikan bahan makanan tertutup dengan baik dan benar, sudah diberikan label sesuai dengan tanggal produksinya.

\section{Saran Akademis}

Bagi peneliti selanjutnya yang memiliki ketertarikan terhadap topik maupun teknik analisis data pada penelitian ini, penelitian ini dapat dijadikan panduan maupun referensi. Peneliti selanjutnya dapat menggunakan topik yang sama seperti peniliti yaitu: Hygiene dan sanitasi, dengan objek yang berbeda seperti penerapan hygiene pada pastry section, steward, FB service. Hygiene dan sanitasi pada dalam penyimpanan freezer atau refrigerator.

\section{DAFTAR PUSTAKA}

BC Cook Articulation. (2015). Dalam W. Anderson, M. Barnett, D. Bensmiller, F. Chong, \& R. Christian, Food Safety, Sanitation, and Personal Hygiene. Vancouver.

Borda, Daniela; Thomas, Miles R.; Langsrud, Solveig; Rychli, Kathrin; Jordan, Kieran;. (2014). Food Safety Practices In European TV Cooking. British Food Journal, Vol 116, 10.

Cong, F. (2017). The Influence Of Knowledge on The Implementation of Sanitasi Hygiene in School Production Unit of Cullinary Art Program Vocational High School. The International Journal of Science And Technology, Vol 5.

Firmansyah, A. (2016, Januari 13). Penyimpanan Makanan. Diambil kembali dari http://recipe-aboutfood.com/penyimpanan-makanan/

Fitriana, I. N., \& Darni, J. (2018). Pengaruh Hygiene dan Sanitasi Dalam Penjualan Makanan. Journal Of Islamic Nutrition , 1(1):2-8.

Food Standard Agency. (2013). Food Hygiene A Guide For Business. Dipetik Juni 2013, dari food.gov.uk

Food Standard Agency. (2018, Mei 15). Legal requirements for meat establishments. Diambil kembali dari https://www.food.gov.uk/businessguidance/legal-requirements-for-meatestablishments

Food Standard Agency. (2018, Januari 19). Packaging and Labeling. Diambil kembali dari https://www.food.gov.uk/businessguidance/packaging-and-labelling

Kementerian Kesahatan RI. (2015, June 18). Keamanan Pangan. Diambil kembali dari

http://mediakom.sehatnegeriku.com/ke amanan-pangan/ 
Milan ASL Preventive Medicine Department. (2013). Food Hygiene. GUIDELINES HYGIENE AND SAFETY FOR FOOD AREA, Volume 2.0 .

Prastowo, Ichwan;. (2017). Hotel Hygiene \& Sanitasi. Yogyakarta: Deepublish.

Sachriani, D., \& Riska, N. (2014, Oktober 28). Sanitasi Dapur. Diambil kembali dari https://www.slideshare.net/tasyalailiak adari/sanitasi-dapur

Simanjuntak, H. (t.thn.). Persyaratan Dapur Yang Baik. Diambil kembali dari https://contohdanfungsi.blogspot.com/ 2012/11/sanitasi-ruang-pengolahanmakanan.html\#

Surono, Inggrid; Sudibyo, Agus; Waspodo, Priyo;. (2016). Keamanan Pangan: Pengantar Keamanan Pangan untuk Industri Pangan. Yogyakarta: Deepublish.

Sutrisno, W., Wulandari, S., \& Sodik, N. (2016). ANALISIS PENERAPAN HOSPITALITY, HYGINE DAN SANITASI PADA USAHAKULINER DIKAWASAN WISATA SETU BABAKAN DI JAGAKARSA JAKARTA SELATAN. Journal of Applied Business and Economics .

Syahadah, Robiul;. (t.thn.). 6 Prinsip Hygiene dan Sanitasi Yang Harus Di Perhatikan. Dipetik April 2018, 4, dari https://environment-indonesia.com/6prinsip-hygiene-sanitasi-yang-harusdiperhatikan/

Topowijono, S. (2018). Hygiene dan Sanitasi dan Minuman. Jurnal Administrasi Bisni, Vol 58, No.2.

U.S Food and Drugs. (2018, Juni 4). Are You Storing Food Safely. Diambil kembali dari

https://www.fda.gov/forconsumers/con sumerupdates/ucm093704.htm

Yardimc, H. (2015). Knowledge Of Food Staff in Catering Industry. Journal Hygiene, Vol 1 
Vol.1 (No.2) : no. 92 - no. 131 . Th. 2018 p-ISSN : 2622-1292

e-ISSN : 2623-0488 